\title{
NBSIR 73-287 \\ Procedures for the Calibration of Volumetric Test Measures
}

John F. Houser

Institute for Basic Standards

National Bureau of Standards

Washington, D. C. 20234

August 1973

Final

Prepared for

Optical Physics Division Institute for Basic Standards National Bureau of Standards Washington, D. C. 20234 

John F. Houser

Institute for Basic Standards

National Bureau of Standards

Washington, D. C. 20234

August 1973

Final

Prepared for

Optical Physics Division

Institute for Basic Standards

National Bureau of Standards

Washington, D. C. 20234

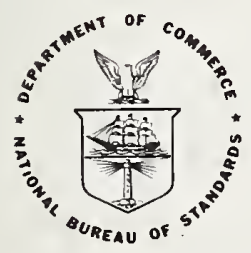

U. S. DEPARTMENT OF COMMERCE, Frederick B. Dent, Secretary

NATIONAL BUREAU OF STANDARDS, Richard W. Roberts, Director 


\section{INTRODUCTION}

The calibration of a volumetric vessel requires the determination of three calibration constants:

1. The containment volume, $V_{C}$, which is the volume of water required to fill the vessel at $60^{\circ} \mathrm{F}$.

2. The delivery volume, $V_{D}$, which is the volume of water which may be poured from the vessel at $60^{\circ} \mathrm{F}$ under specified conditions. $V_{D}$ differs significantly from ${ }_{C}$.

3. The necl constant, $K$, which relates the true volume of neck to the value observed on the neck scale.

There are two methods for obtaining values of these test constants, the choice being based upon apparatus and equipment availability. The volumetric transfer requires previously calibrated vessels and is essentially a counting procedure in which the volume of the test vessel is determined from knowledge of the number of "dumps" of the standard vessel renuired to fill the test vessel. When previously calibrated standard volumetric vessels are not available, the gravimetric method may be used. This requires a balance upon which the mass of water reculred to f 111 the test vessel is measured. From measured values of mass and knowledge of water density, the reauired volumes may be calculated.

\section{SUGGESTED CLEANING AND INSPECTION PROCEDURES}

The vessels are prepared for calibration as follows:

1. Unpack each measure carefully, making special note of any damage that could have occurred to the vessel during shipment.

2. Inspect the vessel carefuliy to be sure that it is free of dents, rust, and broken gage glass. 
3. Biodegradeable detergents are used to clean the interior of the vessels. When necessary, solvents are used prior to cleaning with detergents. Care is exercised in cleaning epoxy coated vessels with solvents as some solvents may cause a reaction which would damage the coating.

4. Each vessel should be filled with water and allowed to stand for several minutes. During this time, an examination is made for leaks. After this inspection is made, the vessel is rinsed with distilled water, then with alcohol; it is then allowed to dry.

5. Smaller vessels, whose level is determined by the plane of the supporting base, should rest on a level bed plate and be checked for firm seating (that is, 3 point support or an adequately flat base). A vessel which rocks will not give a true meniscus reading during the callbration.

6. An information, or summary sheet, is prepared giving the following information. (See sample summary sheet, figure 1.)

a. Identify the vessel or vessels to be tested by owner and test number.

b. List all the vessels, their maker number, identification number, assumed scale divisions and assumed coefficient of expansion.

c. List all other information necessary to make complete record of the test.

\section{EQUIPMENT REQUIRED FOR GRAVIMETRIC CALIBRATIONS}

The vast majority of work of this type involves measurement of volumes ranging from 5 gallons to 100 gallons, and this paper is addressed to workers operating within this range whose requirements are satisfied by an uncertainty of .01\%. For volumes larger or smaller than this, although the general methods are the same, specialized techniques and apparatus are generally called for. It is necessary to either have calibrated volumetric standards scattered conveniently across the range of volumes to be calibrated or a balance of appropriate capacity and reproducibility. 
The following equipment is necessary for the gravimetric method of calibration.

1. Balance or load cell as appropriate to the work level (with a standard deviation of $500 \mathrm{mg}$ or better).

2. Weights (calibrated to about $1: 50,000$ ) as appropriate to the worli level.

3. Thermometer (calibrated to $0.1^{\circ} \mathrm{C}$ ).

4. Barometer or barograph (calibrated to $2 \mathrm{~mm}$ of mercury).

5. Hygrometer (calibrated to $4 \%$ ).

6. Ball Bearings for neck calibration (2 1/2 inch, grade 50).

7. Bed plate (with adjustable legs).

8. Machinist level.

9. Storage tank for water.

10. Mixer (mixing water).

11. Stopwatch.

12. Assorted lengths of pines.

13. Assorted hand tools.

\section{Gravimetric Calibration Procedure}

The general techninue is to determine the mass of water required to fill a vessel and the mass of water clinging to the inside walls of the vessel after draining in the specified manner. The differences between these masses, together with knowledge of water density permits one to calculate $V_{C}$ and $V_{D}{ }^{\circ}$ Although any type weighing procedure of appropriate precision may be used in this work, the general weighing technique called "double substitution" is the mode best adapted to this work. The data sheets illustrated in figures 2,3 and 4 are designed for use with a free-swinging balance. 
Prior to testing, a cap of some kind is placed over the neck opening; this acts as a lid to prevent evaporation of moisture from the vessel. This cap remains on the vessel during the entire weighing procedure.

STEP I - (See data sheet, figure 2.)

Weigh the vessel empty:

Each "double substitution" requires four

observations: $0_{1}, 0_{2}, 0_{3}$, and $0_{4}$ as shown in figure 2 .

$0_{1}$ Place weights on the pan nominally equal to the mass of the vessel and cap. Record the masses of the standard weights used, Msl. For sets of standard weights having duplicate weights, record which weight is used so that the proper true mass correction is selected from the correction table. Turning points are observed on the balance and recorded on the data sheet.

$0_{2}$ The weights are removed and the empty vessel and cap are placed on the pan. Read and record the turning points.

$0_{3}$ A sensitivity weight, $W_{s}$ is added. Read and record the turning points.

$0_{4}$ The vessel is removed and the standard weights are returned to the pan along with the sensitivity weight. Read and record these turning points.

Environmental conditions are recorded before and after each "double substitution". Record $T_{1}, B_{1}$, and $H_{1}$, the air temperature, barometric pressure, and relative humidity respectively on the data sheet in the appropriate spaces. The date, time and description of the work, as well as the observer should also be recorded.

STEP II - (See data sheet, figure 3.)

Weigh the vessel full of water:

From the water storage tank, fill the vessel with water to any point on the neck scale, $\delta_{1}$. This watex should be stored for a day or so after distillation, this allows the water to equilibrate with ambient conditions. After filling the vessel, the water should be mixed thoroughly in order to remove most of the thermal 
gradients which affect the observations leading to the calculated volume. This provides the added benefit of allowing any trapped air bubbles to rise to the surface.

Place the vessel on the bed plate and record the water temperature, $T_{W}$. Making sure that the vessel is level, agitate the water in the gage tube and read the meniscus. Record on the data sheet the meniscus scale reading, water temperature, and mix time. After thoroughly drying all water from the exterior, balance the vessel against the standard weights following the procedure as described in step $I$. Record ambient conditions $\mathrm{T}_{2}, \mathrm{~B}_{2}, \mathrm{H}_{2}$ and standard weights $\mathrm{M}_{\mathrm{s} 2}$.

STEP III - (See data sheet, figure 4.)

Weigh the vessel after draining:

Drain the water from the vessel, holding 1 in the drainage position for a specified interval (usually 1030 seconds) after cessation of the main flow. Reweigh the vessel, recording $\mathrm{M}_{3}{ }$, and ambient conditions $T_{3}, B_{3}$, $\mathrm{H}_{3}$, and drain time.

V. NECK CALIBRATION (See data sheet, figure 5.)

In use, the vessel is not always filled to the same scale reading, $\delta_{1}$, used in calibration but to any point $\delta_{n}$. The volume difference between filing to $\delta_{i}$ (in calibration) and $\delta_{n}$ (in use) may be obtained by neck scale calibration. This is accomplished by filling the vessel to near the bottom of its scale range, $\delta_{A}$ and inserting in the vessel precision spheres of known diameter, $d$, which increase the water level to $\delta_{B}$, $\delta_{C \text { o }}$ etc.

Essentially, this experiment consists of (effectively) adding water volume in known increments and recording the change in scale indications from $\delta_{A}$ to $\delta_{B}$ to $\delta_{C}$. etc. This data permits graphic or analytical evaluation of the scale divisions, $\delta^{\mathrm{s}} \mathrm{s}$, for a value of $\mathrm{K}$ where

$$
K=\frac{\pi d^{3}}{\left(\delta_{A}-\delta_{B}\right)^{6}}
$$


The precision spheres are replaced by known volumes of water for vessels with neck diameters greater than four inches.

In performing a neck calibration, it should be evident that the vessel must be level to insure a true neck calibration.

\section{GRAVIMETRIC CALIBRATION CALCULATION}

Each of the three double substitution weighings, described above, provide a numerical value of the difference between the known and unknown loads. This difference in mass units is calculated from the observed turning points and the value of the sensitivity weight described on the data sheets. It is referred to as an "A". calculated from the formula [l]

$$
\rho_{a}=\frac{464.56 \mathrm{~B}-\mathrm{H}\left(0.085594 \mathrm{~T}^{2}-1.8504 \mathrm{~T}+34.47\right)}{(\mathrm{T}+273.16) 1,000,000}
$$

where

$$
\begin{aligned}
& \rho_{\mathrm{a}}=\text { Density of air in } \mathrm{grams} / \mathrm{cm}^{3} \\
& B=\text { Pressure in mm of } \mathrm{Hg} \\
& \mathrm{H}=\text { Relative humidity in percent } \\
& \mathrm{T}=\text { Temperature of air in } \\
& \text { degrees Centigrade. }
\end{aligned}
$$

This calculation is also indicated on the raw data sheet.

[1] Bowman, H. A., and Schoonover, R. M., NBS Journal of Research, C. Engineering and Instrumentation, Vol. 71C, Page 182 . 
One may now write three enuations describing the three substitution weighings using the three numerical values of " $A$ ", $A_{1}, A_{2}$ and $A_{3}$, and a value of air density associated with each "A" $\rho_{1}, \rho_{2}$ and $\rho_{3}$.

$$
A_{1}=\dot{M}_{j}-\rho_{l} V_{j}-M_{s l}+\rho_{l} V_{s_{l}}+\text { measurement error }
$$

where $M_{j}=$ Mass of the vessel

$\mathrm{V}_{j}=$ Metallic volume of the vessel

$\mathrm{V}_{\mathrm{s} I}=$ Total volume of mass standards

$$
A_{2}=M_{j}-\rho_{2} V_{j}+M_{w}-\rho_{2} V_{w}-M_{s_{2}}+\rho_{2} V_{s_{2}}+\text { measurement error }
$$

where $\mathrm{V}_{\mathrm{W}}=$ Volume of water contained

$\mathrm{M}_{\mathrm{W}}=$ Mass of the water

$$
A_{3}=M_{j}-\rho_{3} V_{j}+M_{R w}-\rho_{3} V_{R w}-M_{s 3}+\rho_{3} V_{s 3}+\text { measurement error }
$$

where $\mathrm{M}_{\mathrm{Rw}}$ = Mass of water retained

$\mathrm{V}_{\mathrm{RW}}=$ Volume of water retained

The measurement error term in the three foregoing equations will be discussed in detail in a future issue of overLAP. It is not included in subsequent equations below inasmuch as it does not enter into the calculation of a single calibration test.

The mass of water, $M_{W}$, may be calculated from the difference between equations 1 and 2 .

$$
M_{W}=\frac{A_{2}-A_{1}+M_{S_{2}}-M_{S_{1}}+\rho_{1} V_{S_{1}}-\rho_{2} V_{S_{2}}}{1-\frac{\rho_{2}}{\rho_{W}}}
$$

Detailed examination of the algebra leading to the above equation for $M_{w}$ will show the term $V_{j}\left(\rho_{2}-\rho_{1}\right)$. This term is believed to be acceptably close to zero under ordinary variability in air density so it is ignored.

Using the observed water temperature, $\mathrm{T}_{\mathrm{W}}$, we obtain a value of water density, $\rho_{w}$, by interpolation in table 1 . The value of $V_{w}$, the contained volume of water in the vessel up to neck reading $\delta_{j}$ may be written 


$$
V_{W}=\frac{A_{2}-A_{1}+M_{S 2}-M_{S 1}+\rho_{1} V_{S 1}-\rho_{2} V_{s 2}}{\rho_{w}-\rho_{2}}
$$
This value for $V_{W}$ which is also the containment volume $V_{1}$ of the
vessel is valid only for the observed water temperature $T_{W^{*}}$ By convention, vessel volumes are always referenced to a temperature of $60^{\circ} \mathrm{F}$. For the conversion from the centigrade scale to fahrenheit scale use the formula ${ }^{\circ} \mathrm{F}=9 / 5^{\circ} \mathrm{C}+32$. To compute a change in known volume, $V$, at temperature $T$, to a volume $V$ at a reference temperature $60^{\circ} \mathrm{F}$ the following formula is used:

$$
V_{t}=V_{1}[1+\alpha(60-T)]
$$

where $\alpha=$ the cutical temperature coefficient of expansion $/^{\circ} \mathrm{F}$ of the vessel

The volume of the residual. vater, $V_{R w}$, is obtained from the difference between equations 1 and 3 .

$$
V_{R W}=\frac{A_{3}-A_{1}+M_{S_{3}}-i_{s_{1}}-\rho_{3} V_{S_{3}}+\rho_{1} V_{S_{1}}}{\rho_{W}-\rho_{3}}
$$

The delivery volume, $V_{D}$, of the vessel when drained as specified after filling to neck graduation $\delta_{i}$, will be

$$
V_{D}=V_{W}-V_{R w}
$$

The calculated results, $V_{\mathrm{H}}$ and $\mathrm{V}_{\mathrm{Rw}}$, of equations 4 and 6 are in cubic centimeters if the welghts are in grams, and air and water density in grams per cubic centimeter.

The volume delivered, $V_{D}$ of equation 7 , is from the fill point $\delta$. and can be expressed to a reference point $\delta_{0}$ by the following modification:

$$
\mathrm{V}_{\mathrm{D}}=\mathrm{V}_{\mathrm{W}}-\mathrm{V}_{\mathrm{RW}}-\left(\delta_{\mathrm{i}}-\delta_{0}\right) \mathrm{K}
$$

By custom $\delta_{0}$ is zero on the graduated scale ana equation 8 can be simplified as follows:

$$
V_{D}=V_{W}-V_{R W}-K \delta_{i}
$$

o's are not always in the same units as $V_{w}$ and $V_{R w}$ and may require further conversion. 
This completes the gravimetric calibration of the unknown vessel, and at this point it is appropriate to introduce a check standard measurement using the newly calibrated vessel as a reference. Assuming prior knowledge of the containment volume of the check standard, the correctness of the delivery volume, equation 9 , may be quickly verified by pouring water from the vessel into the check standard.

The use of the check standard test is a routine procedure in many measurement laboratories and is highly recommended by NBS. It is desirable to maintain a permanent record of the measurements on each check standard because the spread of data among such measurements is descriptive of the process performance and the degree to which traceability to NBS may be demonstrated. The advantages and analysis of check standard data is discussed in the next issue of OVERLAP.

(See appendix for sample calculation for equations 4-8).

\section{Volumetric Calibration Procedure}

A second procedure is available to calibrate volumetric vessels. This method is called the "volumetric transfer" method. It is essentially performed by transferring a known volume of water from a standard vessel into a vessel of unknown volume and calculating either a contained or delivered volume of the unknown vessel. This procedure is usually performed above the 10 gallons level.

Because of the various sizes of vessels, handling becomes a problem. The ideal situation would be to have a platform elevator and a large storage tank for water. Assuming the ideal situation, the "transfer" operation can be performed in the following manner.

(1) An inspection and cleaning process is performed on the unknown vessel, as described in section II, noting any defects such as leaking gage tubes, leaky valves and leaky seams. 
(2) Select a standard vessel, U, of known delivery volume at a specified reference temperature and scale graduation and a known thermal coefficient of expansion, $a$, (cublc). The standard is placed on the platform elevator. along with an attached selected section of pipe, raised to a height appropriate for the test.

(3) Place the unknown vessel, Z, below the standard vessel. Level the unknown vessel either by the attached or built-in levels or by placing a level across the top of the open neck. It is important to use the same leveling procedure when using the unknown vessel as a known vessel at a later date. Attach a piece of pipe from the drain valve of the vessel to a water drain.

(4) A data sheet (see figure 6) is filled out, giving information pertaining to the unknown vessel being calibrated.

(5) If the vessel is to be calibrated for capacity, the internal surfaces of the unknown must be dry; for delivery, both the standard and the unknown must be wet. They are wetted by filling the standard and transferring the water into the unknown with a thirty second drain time after cessation of the main flow. Drain the unknown in a similar manner. This process is only for wetting the surfaces.

(6) Level the standard vessel. Fill the standard vessel, $U$, to any point on the neck scale, La, with water from the storage tank. Record the water temperature, $\mathrm{T}_{\mathrm{A}}$, on the data sheet. Agitate the water in the gage tube to get a uniform meniscus. Read the meniscus scale reading and record the reading on the data sheet. 
(7) Drain the standard in such a maner so as not to lose any water being transferred into the unknown. In some cases it is advisable to place a finger over the opening of the gage tube of the unknown to prevent water from escaping due to pressure. Time the drain for a specifled interval (usually 30 seconds after cessation of the main flow.)

(8) With the unknown standing in a level position, agitate the water level and read the meniscus scale reading. Record the neck reading, $L_{q}$ and the water temperature $\left(t_{q}\right)$ of the unknown vessels on the data sheet.

(9) In situations where a smaller standard vessel Is used to calibrate a larger unknown vessel, each step (5 thru 8) described above is repeated the appropriate number of times, each time draining the standard and the unknown for the specified time.

(10) After one complete calibration or "run" is finished, a second run may be performed. (This second run serves as a check on the first run.) Drain the unknown for the specified time and repeat steps 5 thru 8 .

(11) A neck calibration, as described in section $V$ is performed. On vessels containing double scale plates, denote whether one scale plate or both scale plates have been calibrated.

VII. Data Reduction for Volumetric Calibration

By convention vessel volumes are always referenced to a temperature of $60^{\circ} \mathrm{F}$. If only one transfer of the standard vessel $U$ is required to complete the calibration of an unknown vessel $Z$,

$$
\frac{M}{\rho_{A}}=U_{60}\left[1+\alpha\left(t_{A}-60\right)\right]
$$

and

$$
\frac{M}{\rho_{Q}}=2_{60}\left[1+\beta\left(t_{Q}-60\right)\right]
$$


where $\rho_{A}=$ water density of the standard

${ }^{\circ} \mathrm{O}=$ water density of the unknown

$M=$ the same mass of water transferred from the standard vessel $U_{60}$ into the unknown vessel $z_{60}$

$\alpha=$ cubical coefficient of expansion $/{ }^{\circ} \mathrm{F}$ of the standard, U

$\beta=$ cubical coefficient of expansion $/{ }^{\circ} \mathrm{F}$ of the unknown, Z.

Since the two masses of water are the same,

$$
\mathrm{Z}_{60} \rho_{\mathrm{Q}}\left[1+B\left(\mathrm{t}_{Q}-60\right)\right]=\mathrm{U}_{60} \rho_{\mathrm{A}}\left[1+\alpha\left(\mathrm{t}_{\mathrm{A}}-60\right)\right]
$$

This expression can be solved for $Z$, which is the volume of interest. This can be either a containment or delivery volume.

$$
z_{60}=\frac{\mathrm{U}_{60} 0_{A}\left[1+\alpha\left(t_{A}-60\right)\right]}{\rho_{Q}\left[1+B\left(t_{0}-60\right)\right]}
$$

The standard vessel, U60, has a known volume up to the zero graduation on the neck scale, $L_{0}$. The difference in volume, $\Delta_{A}$, between $L_{0}$ and $L_{A}$ may be calculated by knowledge of the neck calibration constant. The numerical value of $\Delta_{A}$ is used in the calculation of $\mathrm{Z}_{60} 0^{\circ}$

$$
Z_{60}=\frac{\rho_{A}\left[U_{60}\left[1+\alpha\left(t_{A}-60\right)\right]+\Delta_{A}\right]}{\rho_{Q}\left[1+\beta\left(t_{2}-60\right)\right]}
$$

If a standard vessel, $U$, is used $N$ times to calibrate an unknown vessel $Z$, equation 11 can be modifled for $N$ number of transfers as follows:

$z_{60}=\frac{\rho_{A}\left[U_{60}\left[1+\alpha\left(t_{A}-60\right)\right]+\Delta_{A}\right]+\rho_{B}\left[U_{60}\left[1+\alpha\left(t_{B}-60\right)\right]+\Delta_{B}\right]+\ldots+\rho_{N}\left[U_{60}\left[1+\alpha\left(t_{N}-60\right)\right]+\Delta_{N}\right]}{\rho_{Q}\left[1+\alpha\left(t_{Q}-60\right)\right]}$

The correctness of $Z_{60}$ may now be tested by use of a check standard as previously mentioned.

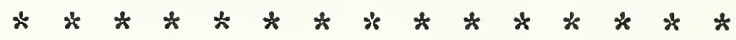


This paper was prepared by John F. House, Mass and Volume Section, Room Al 23 MET, National Bureau of Standards, Washington, D. C. 20234 .

Telephone: Area Code 301 921-2511

U SCOMM-N B STD

$-13-$ 
Date: $6-10-72$

VOLUIETRIC CALIBRATION SURAIARY SHEET

Test performed for:

XYZ Corporation

Items

Maker's Number

Scale

Div.

1 in $^{3} \quad 39-B$

$1 \ln ^{3}$

5

50 Gallon

Maker:

Doe Can Company

Test Number 123456

Property Number

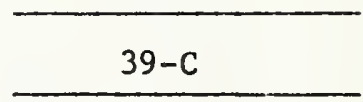

Previous Test No.
Coefficient of

Expansion Assuned

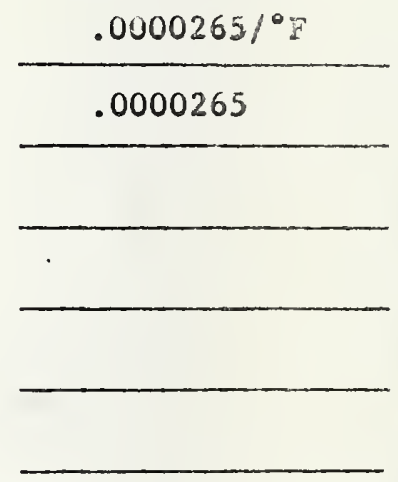

Renarks:

Date Received $6-1-72$

Date Shipped

$7-15-72$ 
Observer A B

5 gallon vessel (graduated neck)

$$
\text { Begin }
$$
Time
Item $6-15-72$

Date
0900 End Time

Sheet Number 1 of 3

Sensitivity Wt. $500 \mathrm{mg}$

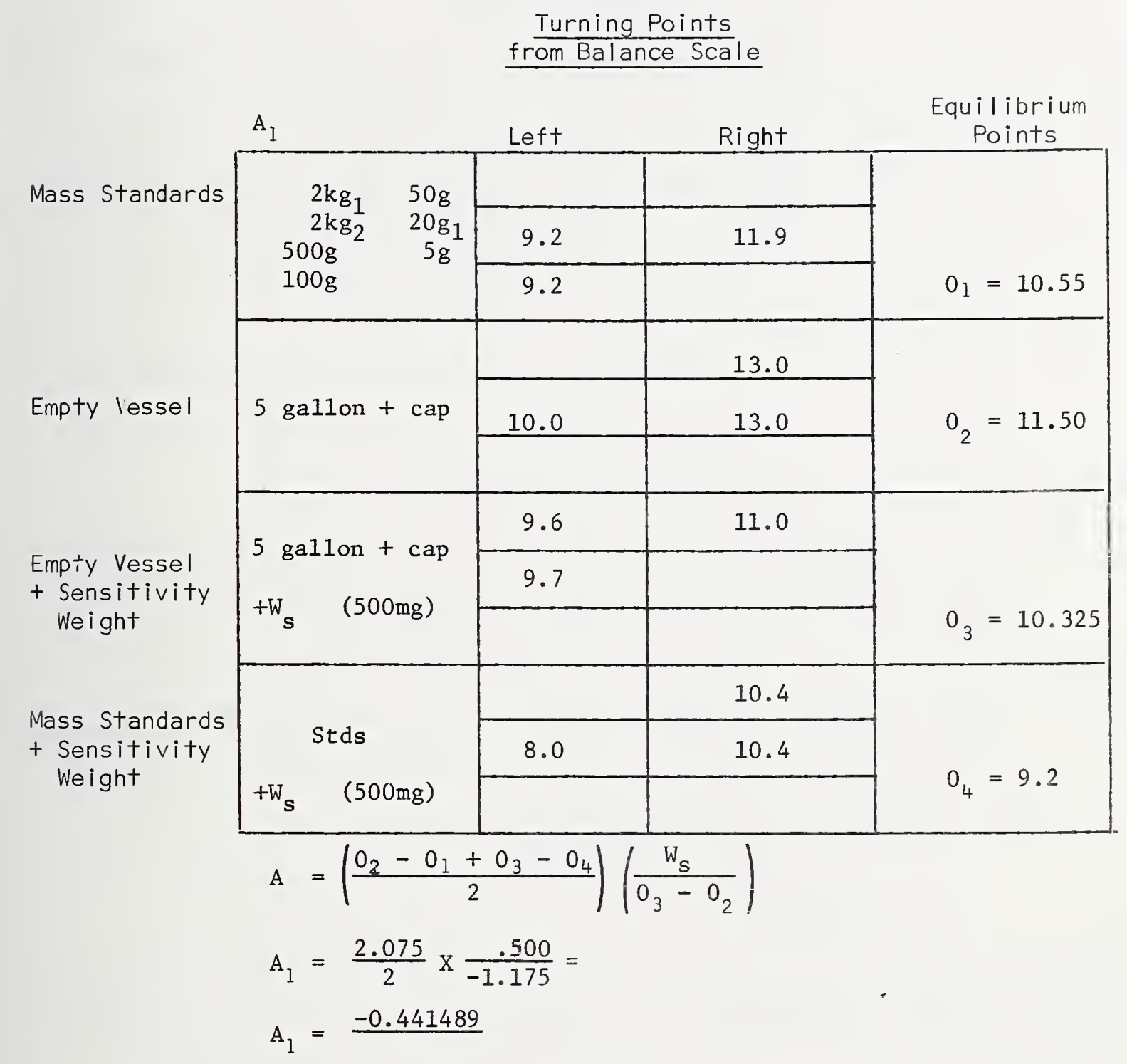

\begin{tabular}{llllll} 
Air Temp. ${ }^{\circ} \mathrm{C}$ & $\begin{array}{c}\text { Begin } \\
25.6\end{array}$ & $\underline{25.7}$ & \multicolumn{1}{c}{$\begin{array}{l}\text { Corr } \\
0\end{array}$} & $\begin{array}{c}\text { Corr Mean } \\
25.65\end{array}$ \\
Barometer mm of $\mathrm{Hg}$ & $\underline{751.04}$ & $\underline{750.90}$ & $\underline{0.35}$ & $\underline{751.32}$ \\
R. H. Reading \% & $\underline{22.1}$ & $\underline{22.0}$ & $\underline{13.05}$ & $\underline{35.1}$ \\
Calculated Air Density $\rho_{1}$ & $\underline{.00116}$ & &
\end{tabular}


Observer A B Test Number

C

Item 5 gallon vessel (graduated neck)

Sheet Number 2 of 3

Date 6-15-72 Time

$\begin{array}{cc}\text { Begin } & \text { End } \\ 0945 & 1010\end{array}$
Sensitivity Wt. $500 \mathrm{mg}$

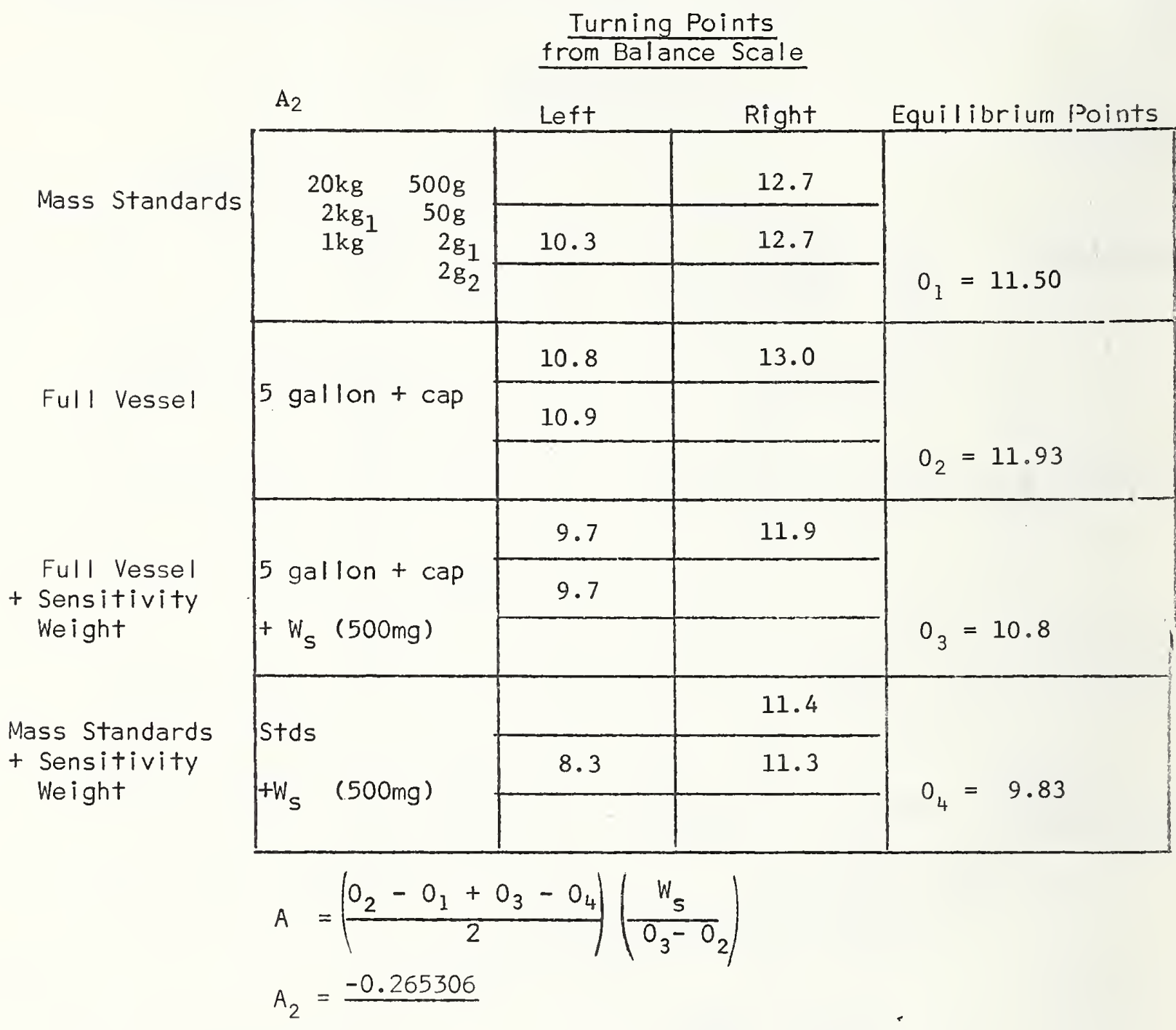

Scale Reading +1.0 div.

Air Temp ${ }^{\circ} \mathrm{C}$

Begin End Corr Corr Mean

Air Temp ${ }^{\circ} \mathrm{C}$

25.8

Barometer $\mathrm{mm}$ of $\mathrm{Hg}$

750.78

$25.9 \quad 0$

25.85

R. H. Reading \%

$750.70 \quad 0.35$

751.09

22.0

22.2

13.0

35.1

$\mathrm{H}_{2} \mathrm{O}$ Temp

$\mathrm{T}_{\mathrm{W}} 24.835$

Mix Time

$5 \min$.

Calculated Air Density $\rho_{2} .00116$ 
Observer

A B Test Number

Bal ance

C

Item 5 gallon vessel (graduated neck)

Date $6-15-72$ Time Begi Sheet Number 3 of 3 Sensitivity Wt. 500mg

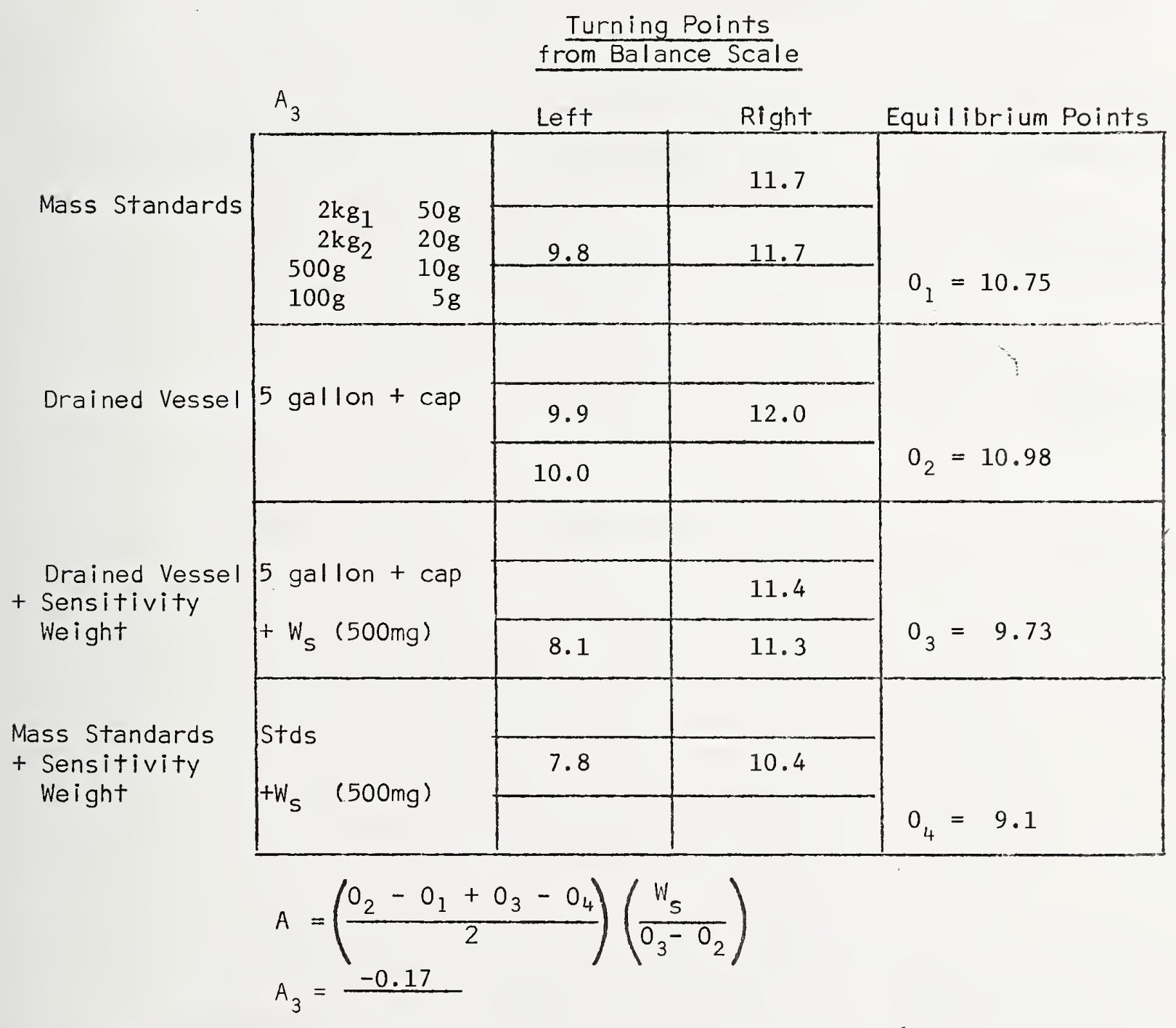

\begin{tabular}{|llllll|}
\hline $\begin{array}{l}\text { Air Temp }{ }^{\circ} \mathrm{C} \\
\text { Barometer mm of hg }\end{array}$ & $\begin{array}{r}\text { Begin } \\
\frac{25.9}{750.68}\end{array}$ & $\frac{25.9}{750.68}$ & $\frac{0}{0.35}$ & $\frac{25.9}{751.03}$ \\
R. H. Reading $\%$ & $\underline{22.2}$ & $\frac{22.2}{13.0}$ & $\frac{35.2}{13}$ \\
Drain Time & 10 sec. & & & Calculated Air Density $\rho_{3}^{.00116}$ \\
\hline
\end{tabular}


Test No: $\quad 123456$

Item: 5 Gallon
Date: $6-15-72$

Observer: JFH

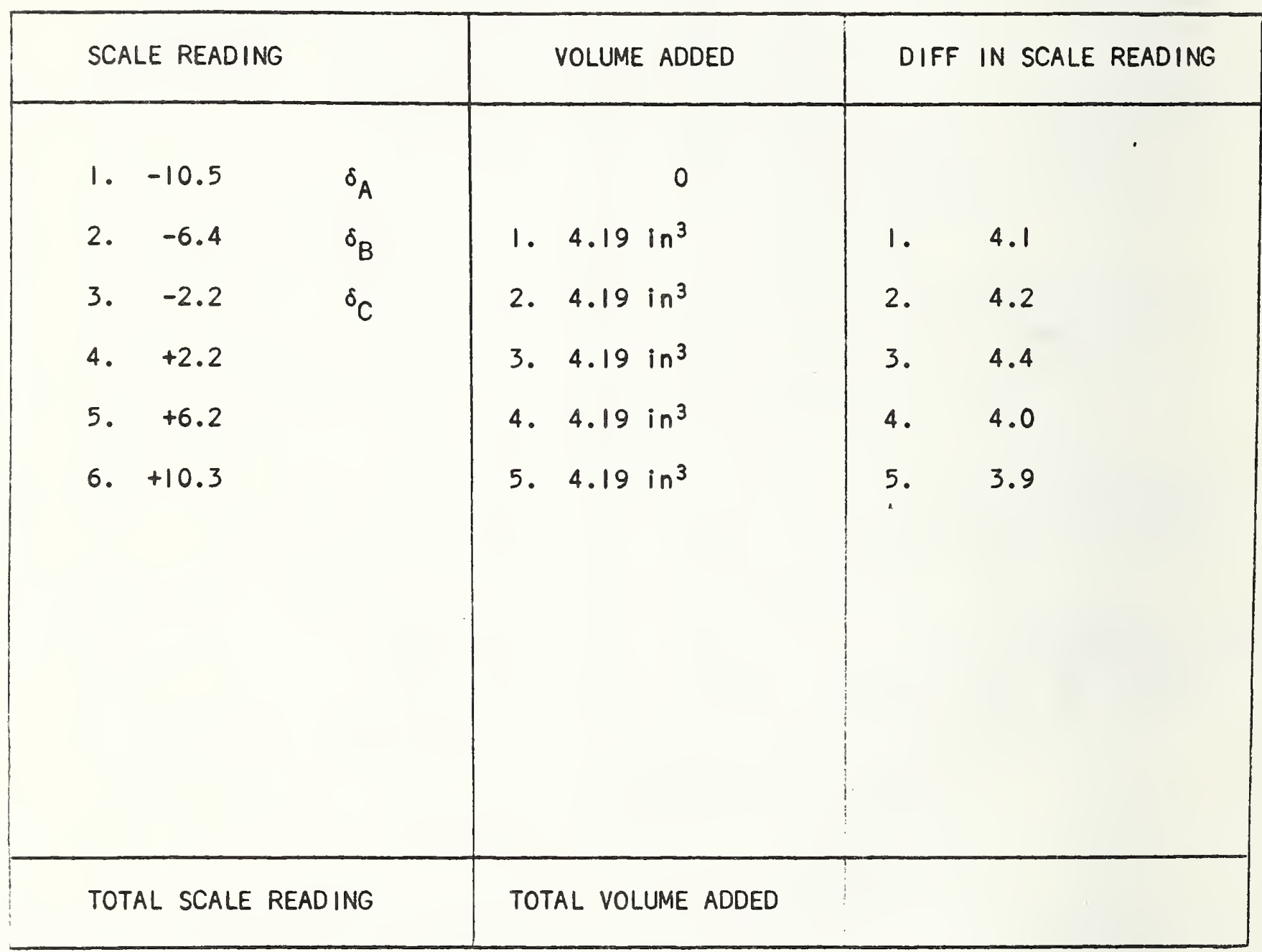

10.5

Figure 5

10.3

20.8 divisions $=20.95 \mathrm{in}^{3}$

1 division $=20.95 \mathrm{in}^{3} / 20.8$

1 division $=1.01 \mathrm{in}^{3}$ 
Nominal Value: 50 Gallon

Type of

Leveling: Attached

Date: $06-12-73$

Assumed Coefficlent of Expansion: 0.0000265 Material: Stainless Steel Scale Division: 1 in $^{3}$

Neck Diameter: 3 3/4"

Type of Value: ball

Water used: Stored

Identification Number: $\quad 39-\mathrm{C}$ To Contain

To Deliver

Standard

\begin{tabular}{|c|c|c|c|c|}
\hline Run & Temperature & $\begin{array}{c}\text { Meniscus } \\
\text { Scale Reading }\end{array}$ & $\begin{array}{l}\text { Nominat } \\
\text { Value }\end{array}$ & $\begin{array}{l}\text { Vol from Zero } \\
\text { e } 60^{\circ} \mathrm{F} \text { in Gallons }\end{array}$ \\
\hline 1 & $21.103^{\circ} \mathrm{C}$ & -12.0 & 50 & 50.0048 \\
\hline \multirow[t]{3}{*}{11} & 20.848 & -8.0 & 50 & 50.0048 \\
\hline & UNKNOWN & & & \\
\hline & Temperature & Scale Reading & & \\
\hline 1 & 21.341 & -12.0 & & \\
\hline 11 & 20.875 & -7.9 & & \\
\hline
\end{tabular}




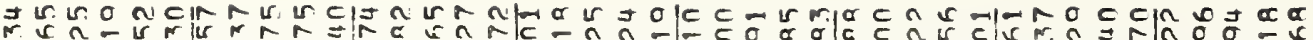

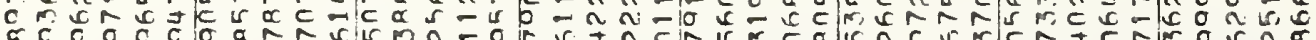

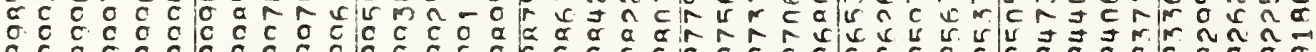

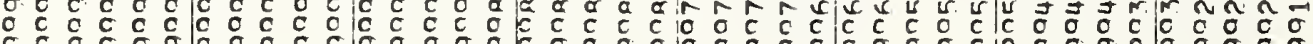

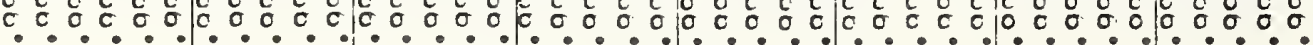

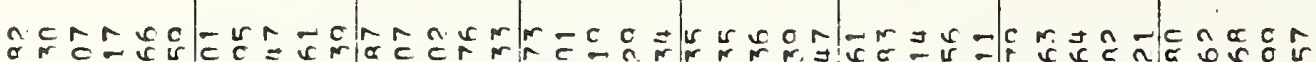

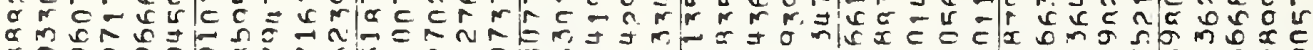

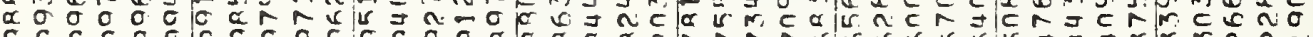

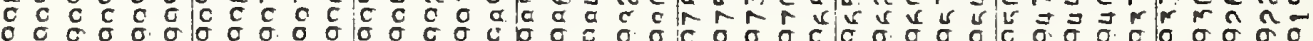
c

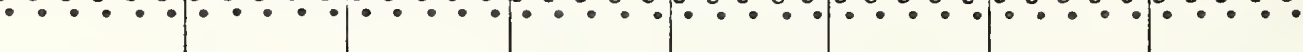

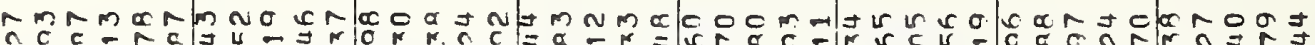

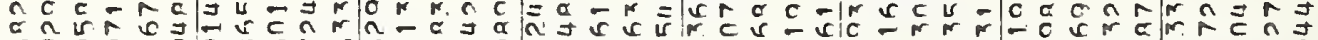

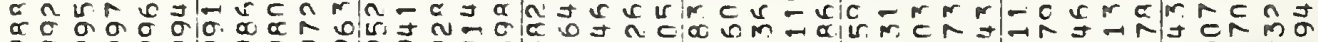
o c.

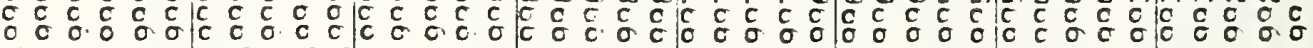

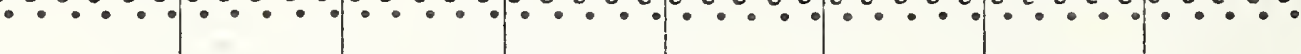

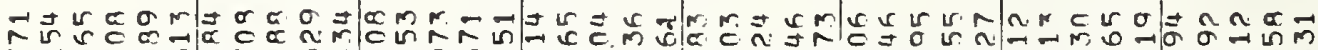
$\hat{A}$ N

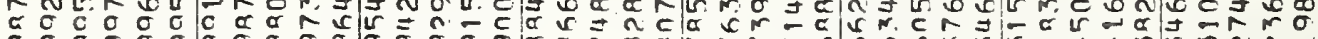

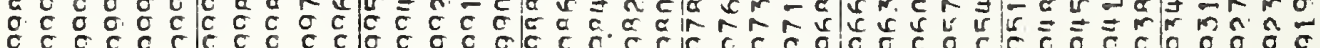

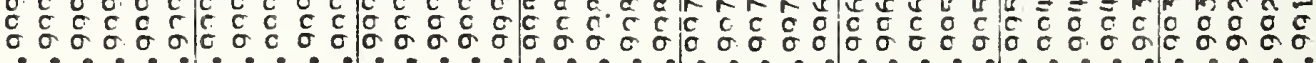

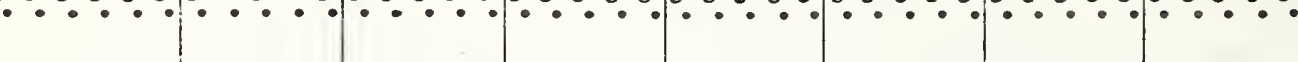

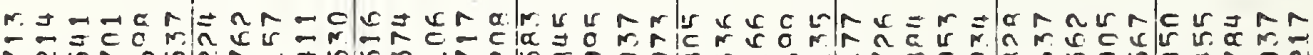

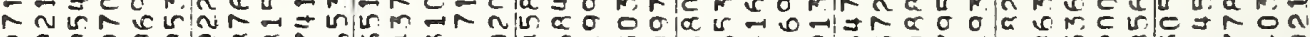

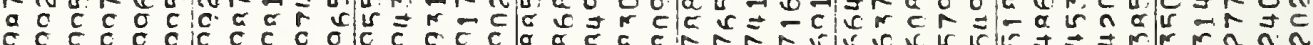

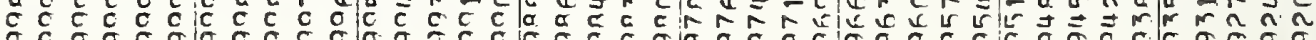

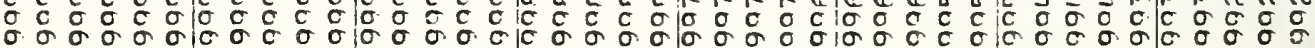

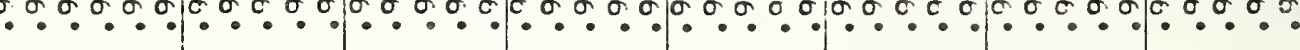

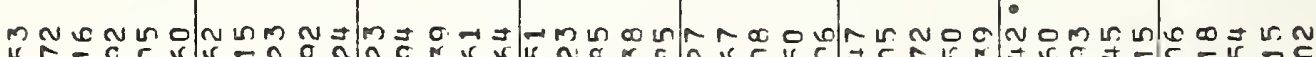

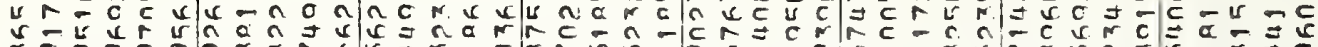

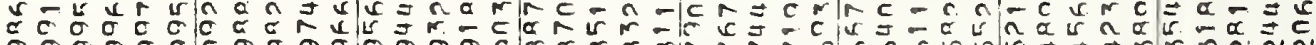

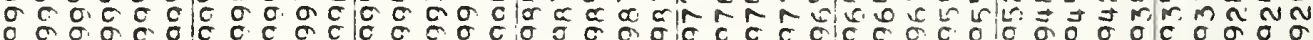

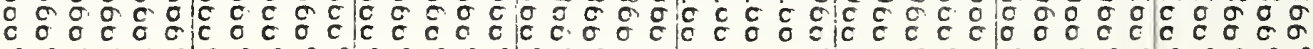

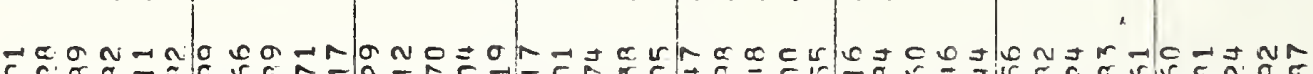

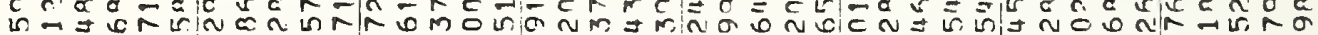

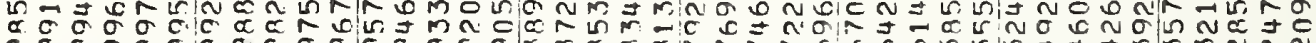

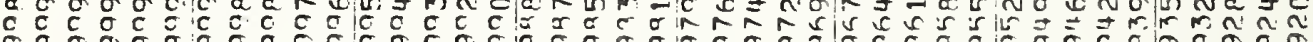

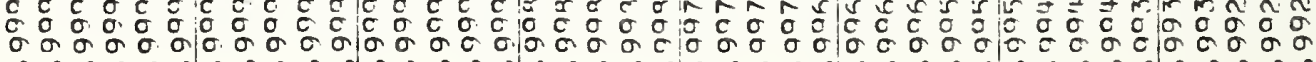
.

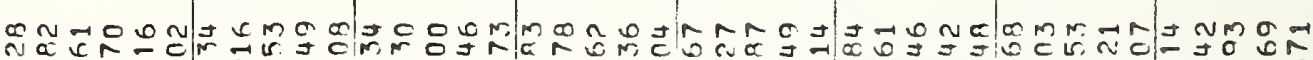

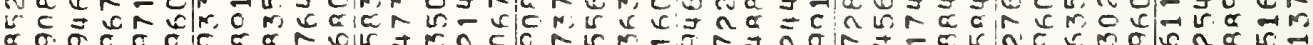

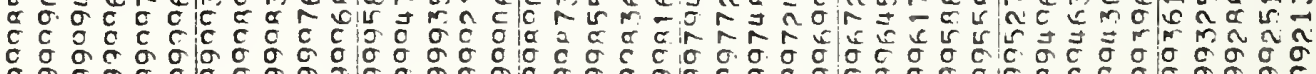

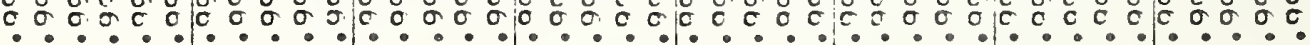

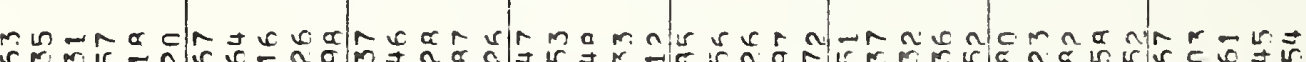

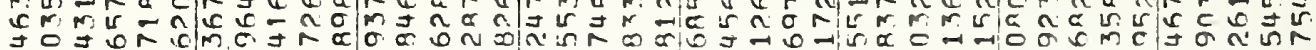

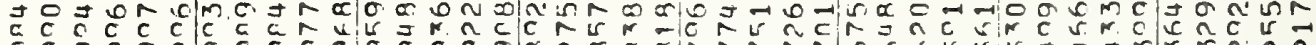

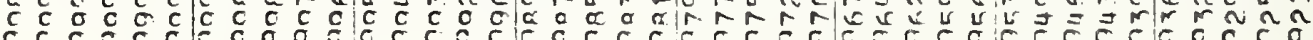
б

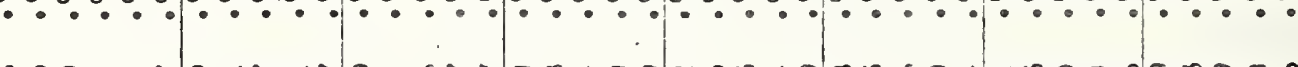

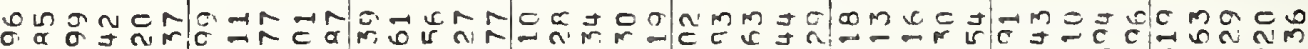

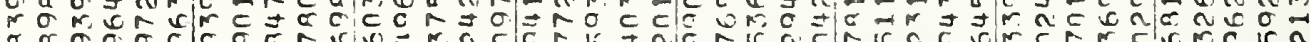

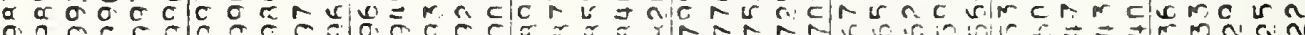

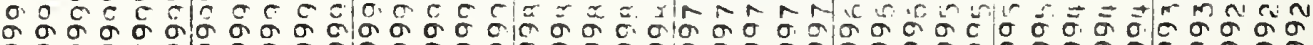

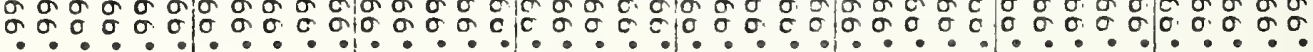

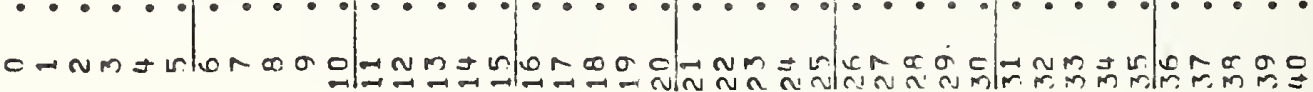


Sample Calculation: for Gravimetric Calibration

From the sample data sheets, the following necessary data is required for the calculation of the test measure volume

1. numerical value for "A" (grams)

2. air density (gram/ $\left.\mathrm{cm}^{3}\right)$

3. corrected mass values (grams)

4. volume for mass standards at test temperature $\left(\mathrm{cm}^{3}\right)$

\begin{tabular}{|c|c|c|c|}
\hline & $\begin{array}{c}\text { Empty } \\
\text { Vesse1 }\end{array}$ & $\begin{array}{c}\text { Ful1 } \\
\text { Vesse1 }\end{array}$ & $\begin{array}{c}\text { Drained } \\
\text { Vesse1 }\end{array}$ \\
\hline "A" & -.441489 & -.265306 & -.17 \\
Air Den. & .00116 & .00116 & .00116 \\
Std. & 4675 & 23554 & 4685 \\
Vol. Stds. & 556.67 & 2804.89 & 557.87 \\
\hline
\end{tabular}

5. coeffient of expansion (Cubical/ ${ }^{\circ} \mathrm{F}$ ), = .0000265

6. corrected water temperature $=24.835^{\circ} \mathrm{C}$ corresponding water density $=.997094 \mathrm{grams} / \mathrm{cm}^{3}$

7. scale reading +1.0 in $^{3}$ (must be converted to gallons)

Substituting numerical values in equation 4

$$
\begin{aligned}
& V_{W}=\frac{-.265306-(-.441489)+23554-4675+0.00116(556.67)-0.00116(2804.89)}{0.997094-0.00116} \\
& V_{W}=\frac{18876.56825}{.995934} \\
& V_{W}=18953.63372 \mathrm{~cm}^{3}
\end{aligned}
$$

To convert from $\mathrm{cm}^{3}$ to gallons multiply by $.00026417 \mathrm{gal} / \mathrm{cm}^{3}$

$$
\begin{aligned}
& \mathrm{V}_{\mathrm{W}}=18953.6337 \times .00026417 \\
& \mathrm{~V}_{\mathrm{W}}=5.00698 \text { gallons }
\end{aligned}
$$


From equation 5 the volume at $60^{\circ} \mathrm{F}$ (conventional reference temperature) is determined.

$$
\begin{aligned}
& \mathrm{V}_{60}=5.00698[1+.0000265(-16.70)] \\
& \mathrm{V}_{60}=5.00476
\end{aligned}
$$

Substituting numerical values in equation 6 :

$$
\begin{aligned}
\mathrm{V}_{\mathrm{RW}} & =\frac{-.17-(.441489)+4685-4675-0.00116(557.87)+0.00116(556.67)}{.997094-0.00116} \\
& =\frac{10.270097}{.995934} \\
& =10.312025 \mathrm{~cm}^{3} \\
& =10.312025 \mathrm{X} .00026417=.002724 \text { gallon }
\end{aligned}
$$

For a delivery volume for equation 7

$$
\begin{aligned}
& 5.00698-.00272=5.00426 \text { at test temperature } \\
& \mathrm{V}_{60}=5.00204 \text { gallons }
\end{aligned}
$$

Scale reading $=+1.0$ in $^{3}=+.00432$ gallon

Volume of water delivered from the scale 0 point at $60^{\circ} \mathrm{F}$ on the graduated neck is 4.9977 gallons. 
FORM NBS.114A $(1.71)$

U.S. DEPT. OF COMM.
BIBLIOGRAPHIC DATA
SHEET

4. TIT LE AND SUBTITLE

Procedures for the Calibration of Volumetric Test Measures UBLICATION OR REPORT NO. NBSIR 73-287

2. Gov' Accession No.

3. Recipient's Accession No.

5. Publication Date

$8-30-73$

6. Performing Organization Code

8. Performing Organization NBSIR 73-287

10. Project/Task/Work Unit No. 2320190

NATIONAL BUREAU OF STAND ARDS

DEPARTMENT OF COMMERCE

11. Contract/Grant No.

WASHINGTON, D.C. 20234

12. Sponsoring Organization Name and Address

Same as above

13. Type of Report \& Period Covered

Final

14. Sponsoring Agency Code

\section{SUPPLEMENTARY NOTES}

16. ABSTRACT (A 200-word or less factual summary of most significant information. If document includes a significant bibliography or literature survey, mention it here.)

The values for graduated neck type volumetric vessels may be obtained by either gravimetric or volumetric calibrations. This text describes the two methods of calibration and the data reduction associated with each method. Procedures for preparing these vessels for test are discussed. Also included are illustrations for data recording.

17. KEY V'ORDS (A!phabetical order, separated by semicolons)

air density; calibration; gravimetric; neck; volumetric; water density

18. AVAILABILITY STATEMENT

S UNLIITED.

FOR OHFICI $R$ L DISTRIBUTION. DO NOT RELEASE TO NTIS.

\begin{tabular}{|l|c|}
\hline $\begin{array}{l}\text { 19. SECURITY CLASS } \\
\text { (THIS REPORT) }\end{array}$ & 22 \\
UNCL ASSIFIED & 22 \\
\hline $\begin{array}{l}\text { 20. SECURITY CLASS OF PAGES } \\
\text { (THIS PAGE) } \\
\text { UNCL ASSIFIED }\end{array}$ & 22. Price \\
\hline
\end{tabular}




